\title{
Deafness heterogeneity in a Druze isolate from the Middle East: novel OTOF and PDS mutations, low prevalence of GJB2 35delG mutation and indication for a new DFNB locus
}

\author{
Avital Adato ${ }^{1}$, Leonid Raskin ${ }^{1}$, Christine Petit ${ }^{2}$ and Batsheva Bonne-Tamir ${ }^{1}$ \\ ${ }^{1}$ Department of Human Genetics, Sackler School of Medicine, Tel-Aviv University, Israel; ${ }^{2}$ Unité de Genetique des \\ Déficits Sensoriels, Centre National de la Recherche Scientifique, Unité de Recherche Associée 1968, Institut Pasteur, \\ Paris, France
}

\begin{abstract}
About $60 \%$ of congenital hearing impairment cases in developed countries are due to genetic defects. Data on the molecular basis of hereditary hearing reflects vast genetic heterogeneity. There are $>400$ disorders in which hearing impairment is one of the characteristic traits of a syndrome. Linkage studies have identified more than $\mathbf{4 0}$ human chromosomal loci associated with non-syndromic hearing loss. So far, 16 of these 40 non-syndromic hearing impairment genes have been identified. We have studied the molecular basis of hearing impairment in four Druze families from the same village in Northern Galilee. The Druze are a small, isolated population in the Middle East practising endogamous marriage. Thus it was expected that a single mutation would account for hearing impairments in all these families. Our results show that at least four different genes are involved. Hearing impairment was caused in one family by a novel mutation in the recently identified OTOF (the DFNB9 gene), by a novel Pendred syndrome mutation (Thr193lle) in another family, and by a GJB2 mutation (35delG also known as 30delG) in the third family. In the fourth family linkage was excluded from all known hearing impairments loci (recessive and dominant) as well as from markers covering chromosomes 11-22, pointing therefore to the existence of another non-syndromic recessive hearing loss (NSRD) locus on chromosomes 1-10. European Journal of Human Genetics (2000) 8, 437-442.
\end{abstract}

Keywords: deafness; mutation; Pendred syndrome; Pendrin; DFNB9; OTOF

\section{Introduction}

Hearing loss is the most frequent sensory defect in humans. Hereditary deafness is classified into syndromic and nonsyndromic (isolate) forms. There are up to 400 known disorders in which hearing loss is associated with a variety of anomalies (such as ocular, musculo-skeletal, renal, nervous and pigmentary disorders). These forms account for $30 \%$ of cases of hereditary hearing impairment in children. ${ }^{1,2}$ The general consensus is that autosomal recessive transmission accounts for some $77 \%$ of the non-syndromic cases, autoso-

Correspondence: Dr Batsheva Bonne-Tamir, Department of Human Genetics, Sackler School of Medicine, Ramat-Aviv 69978, Israel. Tel: +972 3 6409318; Fax: +972 3 6409900; E-mail: bonne@post.tau.ac.il Received 25 August 1999; revised 25 February 2000; accepted 2 March 2000 mal dominant transmission $22 \%$ and the remainder are $X$-linked and mitochondrial. ${ }^{3}$ The causative genes of most of the common syndromes associated with hearing impairments have already been cloned. However, out of some 40 known human non-syndromic hearing impairment loci, only 16 genes have been cloned so far. In some cases it seems that there is overlapping of chromosomal locations between syndromic and non-syndromic loci (such as USH3 and DFNA18, USH1C and DFNB18) or between non-syndromic dominant and non-syndromic recessive loci (such as DFNA8 and DFNB21) and also between syndromic, non-syndromic dominant and non-syndromic recessive loci (such as USH1B, DFNA11 and DFNB2). Furthermore, for some of the identified genes (GJB2, MYO7A and PDS) it has been shown that mutations in the same gene can result in a variety of clinical 
phenotypes and/or different modes of inheritance. ${ }^{4}$ Such variable manifestation in phenotypes may be explained by allelic heterogeneity or by the influence of genetic background.

The Druze are a Middle Eastern Islamic sect who practise an endogamous marriage system. They live in villages scattered throughout the Middle East in southern Syria, Lebanon, Jordan and Israel. All four families - BT132A, BT132B (Figure1), BT135 and BT136 (Figure2) studied in this work, live in the same village in Northern Galilee. These families were previously studied and described by Baldwin et al. ${ }^{5}$ Here we report the results of further studies.

\section{Subjects and methods Subjects}

Blood sampling and clinical evaluation were as described by Baldwin et al. ${ }^{5}$ Pedigrees of two of these families (BT132A, BT132B) are shown in Figure1. In the two other families, BT135 and BT136, blood samples of additional members were collected and included in our study.

\section{Marker typing}

Genomic DNA extracted from blood samples of members of the four families was used as a template. Haplotypes were constructed by using typing results of 85 polymorphic markers spanning known hearing loss loci. Members of family BT136 were also typed for polymorphic markers covering all regions of chromosomes11-22. PCR amplification of these markers was performed using pairs of specific primers as described by Sambrook et al. ${ }^{6}$ Alleles of each marker were numbered according to their relative mobility on FMC's Long Ranger $^{\mathrm{TM}}$ Gel (Rockland, ME, USA).

\section{Mutation detection}

DNA Sequencing Exons of the GJB2, PDS and OTOF genes were amplified, from genomic DNA of normal and affected family members, and gel purified by Qiagen gel extraction kit (Hilden, Germany). Nucleotide sequences of primers used for the amplification of these genes exons were previously described by Kelsell et $\mathrm{al}^{7}$ Everett et $\mathrm{al}^{8}$ and Yasunaga et $\mathrm{al}^{9}$ respectively. The purified fragments were used as templates in

BT132A

BT132B

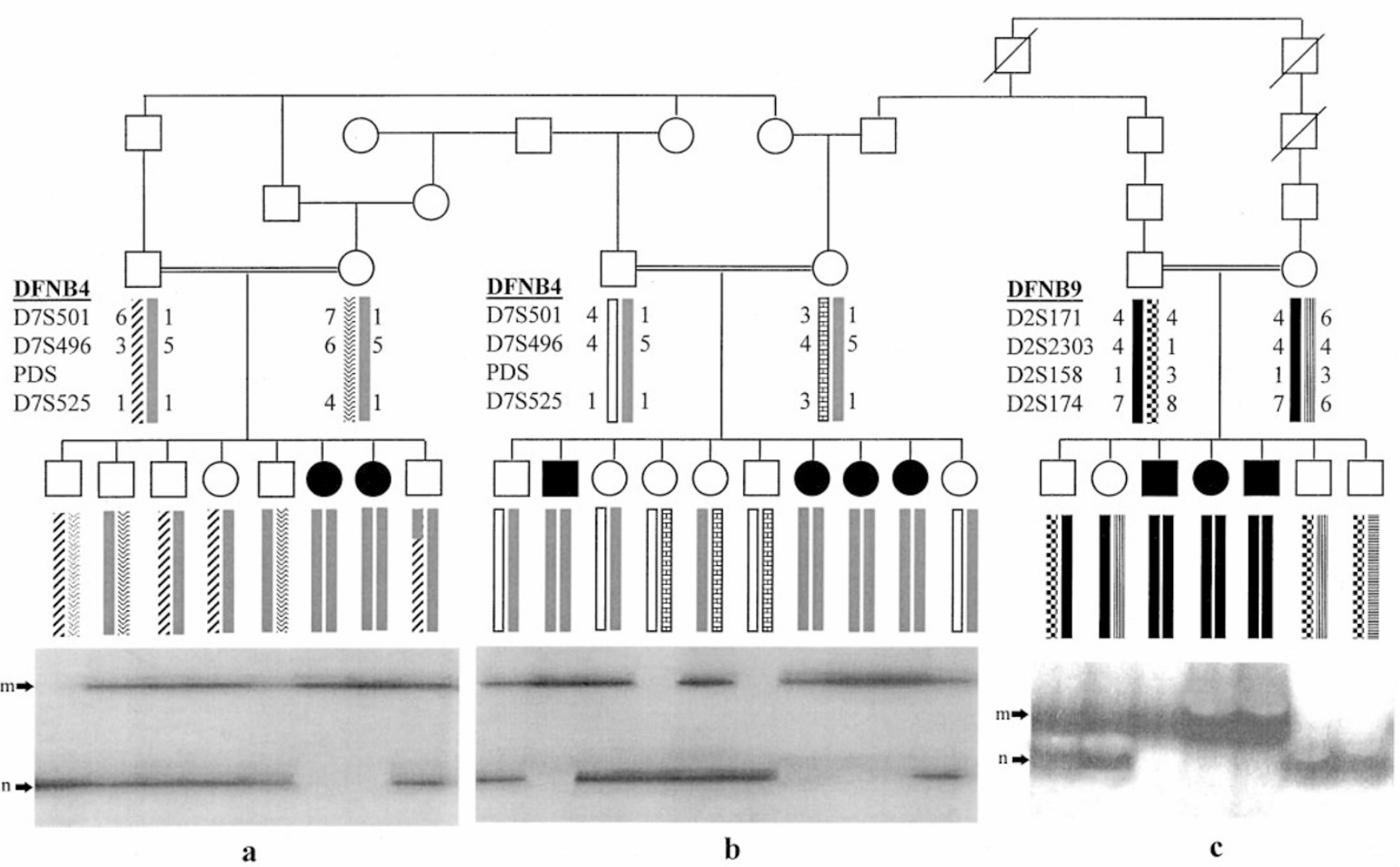

Figure 1 Pedigrees of families BT132A and BT132B which are known to be related. Haplotype segregation is presented for each family. In familyBT132A haplotypes are constructed of polymorphic markers spanning the Pendred/DFNB4 locus on chromosome 7q31. In familyBT132B haplotypes are constructed of polymorphic markers spanning the DFNB9 locus on chromosome2p23-p22. a and b: PDS exon 5 SSCP results, c: OTOF exon 5 SSCP results. Mobility shifts are detectable for family members who carry the mutated exons. m: mutated, n: normal. 


\section{$\underline{\text { OTOF (exon 5) }}$}

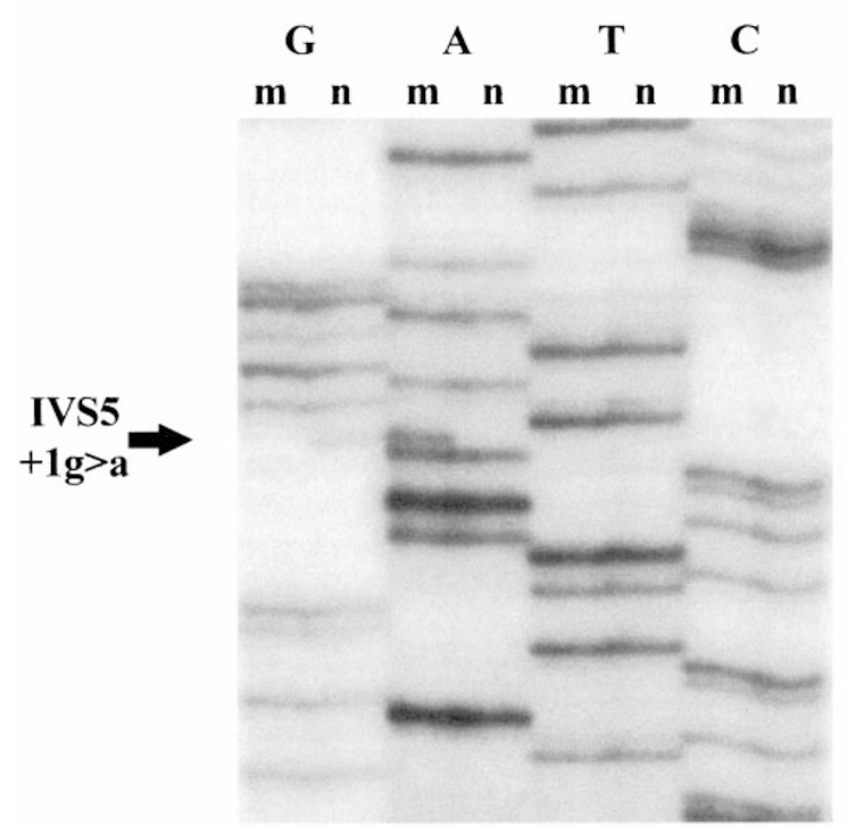

PDS (exon 5)

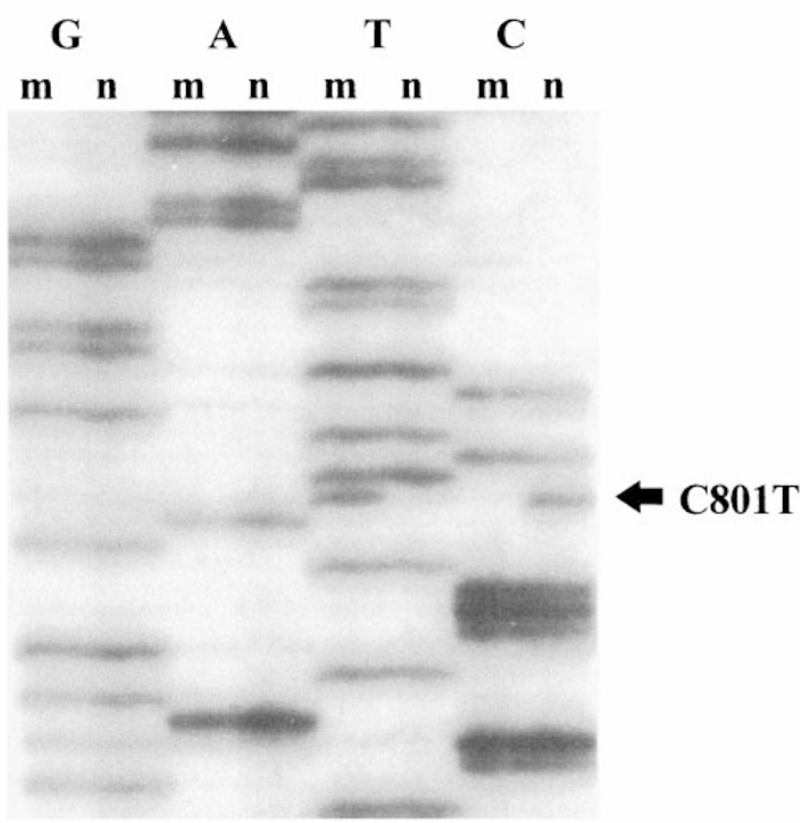

Figure 2 PCR cycle-sequencing (by SequiTherm EXEL ${ }^{\mathrm{TM}}$ DNA Sequencing Kit Epicenter Technologies) of affected (m) and non-carrier (n) family members, were electrophoresed side by side through Long Ranger ${ }^{\mathrm{TM}}$ Gel (FMC). The IVS $+1 \mathrm{~g}>\mathrm{a}$ and T801C mutations are indicated by arrows.

direct cycle sequencing reaction by Epicentre Technologies SequiTherm EXCEL ${ }^{T M}$ II DNA Sequencing Kit (Madison, WI, USA). Sequencing products were subjected to comparative electrophoresis through FMC's Long Ranger ${ }^{T M}$ Gel (Rockland, ME, USA). In comparative electrophoresis normal and shifted sequencing products are el ectrophoresed side by side (normal ddGTP product next to shifted ddGTP product, normal ddATP product next to shifted ddATP product etc); such electrophoresis enables fast and easy detection of homozygous and heterozygous sequence changes.

Occurrence of the GJB2 35delG mutation among 100 unrelated Druze controls was evaluated by the use of site-directed mutagenesis followed by BsiYl digestion as described by Storm et al. ${ }^{10}$ Occurrence of the PDS Thr193Ile mutation among 50 Druze controls and 60 controls of mixed origin, was evaluated by amplification of exon 5 PCR and Tfil digestion. The Single Strand Conformation Polymorphism (SSCP) technique ${ }^{11}$ was used to screen for the occurrence of OTOF IVS5 + $1 \mathrm{~g}>$ a mutation. OTOF exon 5 was PCR amplified from genomic DNA, of 60 Druze and 60 other controls of mixed origin, in the presence of radioactively end-labelled primers. These PCR products were electrophoresed through $M^{M D E}{ }^{T M}$ (AT Biochem) gels, also now from FMC ${ }^{T M}$ (Rockland, $\mathrm{ME}$, USA) gels containing $10 \%$ glycerol, at $800 \mathrm{~V}$ for 16-20h.

\section{Results}

In three consanguineous families; BT132A, BT132B (Figure1) and BT135 severe to profound congenital hearing loss with full penetrance at birth was inherited as an autosomal recessive trait. Affected members of the BT132A family were first diagnosed as affected with recessive nonsyndromic hearing loss. ${ }^{5}$ Recent tests showed that they have goitre and therefore their diagnosis was redefined as Pendred syndrome (MIM 274600). Affected members of family BT136 showed phenotypic heterogeneity since one of the four affected members of this family had post-lingual onset. He started to lose his hearing at the age of 9-10, whilst in other affected family members hearing loss was congenital. Now, at the age of 19 , he has severe-to-profound hearing loss which seems to be a little less profound than that of his affected siblings.

\section{Linkage screening}

Hearing impairment in family BT132A was known to map to the DFNB4/Pendred locus on the chromosomal region of 7q21-34. ${ }^{5}$ All members of the other three families (BT132B, BT135 and BT136) were typed for polymorphic markers spanning known hearing impairment loci (recessive and dominant). In familyBT132B segregation of haplotypes constructed from marker alleles resulted in the exclusion of linkage to the DFNB1-8, the DFNB10-16 and to the DFNA1- 
DFNA13 Ioci. In this family, linkage was suggested only to the DFNB9 locus (OTOF gene) on the chromosomal region 2p22-23 (Figure1). In familyBT135 segregation of haplotypes constructed from marker alleles resulted in the exclusion of linkage to the DFNB2-16, the DFNA1-2 and to the DFNA4-13 loci. In this family, segregation of the marker D13S175 showed significant evidence for linkage $(Z>3)$ to the DFNB1/DFNA3 locus on the chromosomal region $13 q 12$. Segregation of haplotypes constructed from marker alleles of the fourth family, BT136, resulted in the exclusion of linkage to all known recessive (DFNB1-DFNB25) and dominant (DFNA1-DFNA19) hearing impairment loci. Further typing of polymorphic markers, distributed at distances of about $10 \mathrm{~cm}$ along each chromosome, in members of this family resulted in the exclusion of all regions on chromosomes 1122. These exclusion results were not changed when segregation analysis was performed under the consideration of individual 1844 as a phenocopy.

\section{Mutations}

Screening of the relevant genes was conducted by direct sequencing. M embers of family BT132A were screened for the presence of mutations in the PDS gene. A C > T transition at position 801 (Figure2) in exon 5 of the gene was found. This transition, which is predicted to result in a Thr193Ile amino acid substitution in the gene's peptide product, segregated with the disease in the BT132A family but was not carried by any member of family BT132B. The $801 \mathrm{C}>\mathrm{T}$ transition was not detected in 50 unrelated healthy Druze controls, although it was found to be carried by one Moroccan individual out of 50 healthy controls ( 100 chromosomes) of mixed origin who were tested for its presence.

Members of family BT132B were screened for the presence of mutations in the OTOF gene. The only known Y730X mutation ${ }^{9}$ was not found to be carried by members of this family. However, sequencing of exon 5 in affected family members showed a homozygous $\mathrm{g}>\mathrm{a}$ transition at position +1 , the first intronic nucleotide in the splice-donor site of exon 5 (Figure2). This transition which is expected to impair the exon's splice-donor site, was found to segregate with the disease in family BT132B but was not carried by any member of family BT132A. IVS5 $+1 \mathrm{~g}>$ a was not detected in 60 unrelated healthy Druze controls ( 120 chromosomes) nor in 60 healthy controls of mixed origin who were tested for its presence.

Members of family BT135 were screen ed for the presence of mutations in the coding sequence of the GJB2 gene. Direct sequencing of this gene's coding exon showed a homozygous guanine deletion in a sequence of $6 \mathrm{Gs}$ at position 30-35 (35delG also named 30delG). This deletion was found to segregate with the disease in the BT135 family and was not detected in 100 unrelated healthy Druze controls (200 chromosomes) tested for its presence.

\section{Discussion}

One mutation in the OTOF gene (OMIM 603681), was recently found to be responsible for hearing loss in all affected members of four unrelated DFNB9 Lebanese kindreds. ${ }^{9}$ The OTOF is predicted to encode a 1230 amino acid protein homologous to the $\mathrm{C}$. el egans spermatogenesis factor FER-1 and human dysferlin (OMIM 603009). ${ }^{9}$ IVS5 + $1 \mathrm{~g}>\mathrm{a}$, the novel OTOF mutation which was found to be carried by BT132Bfamily members, is the second deafness-associated mutation identified in this gene. The great majority of point mutations identified within donor splice sites occur in the $+1 \mathrm{~g}$ residue, and in $64 \%$ of these cases the substituting base is an adenosine. ${ }^{12}$ This IVS5 $+1 \mathrm{~g}$ transition is expected to result either in exon skipping or in frameshift due to cryptic splice-site usage. Both possibilities would seriously impair the proper production of normal OTOF mRNA. Thus, the two known OTOF mutations (Y730X and IVS5 $+1 \mathrm{~g}>\mathrm{a}$ ) should result in a significantly altered protein. Detection of this novel mutation in our family independently confirms the OTOF gene as the DFNB9 causative gene and demonstrates that there is more than one OTOF mutation that causes hearing impairments among Middle Eastern DFNB9 families.

The PDS gene (MIM 274600) is part of a highly conserved gene family that encodes highly hydrophobic proteins containing the sulphate transporter signature and was found to be expressed at high level only in the thyroid. ${ }^{8}$ Mutations in this gene were found to cause Pendred syndrome, nonsyndromic recessive hearing loss (DFNB4) and non-syndromic sensorineural hearing loss with enlarged vestibular aqueduct (EVA) ${ }^{8,13-15}$ So far, 28PDS mutations, ${ }^{15}$ have been reported to cause Pendred syndrome. Nine of these 28 mutations are missenses that occur at amino acid positions highly conserved among several other sulphate transporters from different species (human Down-regulated in adenoma protein, human diastrophic dysplasia protein, mouse sulphate transporter protein and rat sulphate amino transporter 1), indicating their importance in the protein. ${ }^{13} \mathrm{~T} 193 \mathrm{l}$, the novel Pendred mutation which was found to be carried by BT132Afamily members, is also a missense that occurs at a highly conserved position. In this case a bipolar amino acid residue (thr) at one of the highly conserved positions of the third transmembrane domain is changed to a nonpolar internal residue (ile).

Mutations in the connexin-26 (GJB2) (MIM 121011) were found to be responsible for recessive and dominant nonsyndromic hearing loss ${ }^{7,16}$ and to three different forms of syndromic hearing loss. ${ }^{7,17,18}$ Connexin-26 (GJB2) is a member of a large family of proteins involved in formation of gap junctions. ${ }^{7}$ More than 40GJB2 mutations have been identified so far in deaf patients of different origins. ${ }^{19}$ The 35 delG mutation, that was found to be carried by BT135family members, is the most common GJB2 mutation. ${ }^{19-21}$ It results in a gly to val substitution introducing a stop codon at 
position 13 , which leads to translation of a truncated protein lacking most of its original length. Severity of hearing loss associated with homozygous 35delG mutation was found to vary from mild to profound. ${ }^{22,23}$ Clinical evaluations of BT135 affected members indicated severe to profound congenital hearing loss. Carrier frequency of the $35 \mathrm{del}$ G mutation among general Druze population was found to be much lower (0/100individuals) than the frequencies observed among Mediterranean populations, ${ }^{24}$ American Caucasians of Northern and Southern European origin ${ }^{25}$ and among Midwestern United States population, ${ }^{26}$ all showing carrier frequencies higher than $2 \%$. A carrier frequency, lower than $1 \%$ was also seen in the Israeli Ashkenazi population. ${ }^{27}$

Exclusion results in familyBT136 indicate the probable existence of a new non-syndromic recessive hearing impairment locus somewhere on chromosomes1-10. Due to phenotypic heterogeneity, the involvement of more than one hearing impairment gene in this family cannot be ruled out.

The Druze are a homogenous ethnic population practising endogamous marriage. In such populations a classic founder effect is expected to be involved in the inheritance of genetic diseases. Interestingly, our results indicate that at least four different genes are associated with hearing impairments in the four Druze families from one village included in this work.

Several studies of genetic disorders (Hurler syndrome, metachromatic leukodystrophy and deafness) among Druze and Muslim Arab villages from the Galilee in Israel show the feature of multiple mutations arising within genetic isolates of recent history. ${ }^{28-30}$ This phenomenon seems to be surprising in the light of the common assumption that founder effect is responsible for rare diseases among inbred populations in small geographic areas. Carrasquillo et $\mathrm{al}^{30}$ found allelic diversity of GJB2 mutations in a small Israeli Arab population with high rates of consanguinity. They argued that such mutation distributions are a direct consequence of the population structure in these villages, where very high inbreeding rates, determined both by intense cultural consanguinity and by the recent common ancestry, increase the chance of any rare variant or mutation to become homozygous.

By combining the same arguments suggested by Carrasquillo et $\mathrm{al}^{30}$ with the high heterogeneity which is known to be associated with hearing loss, one can explain the high locus diversity demonstrated in this work.

Therefore, when addressing genetic screening and counselling in such small isolates, population structure should be considered since inbred communities may uncover, rather than reduce, allelic diversity. Furthermore, due to the highly intricate molecular mechanisms controlling the development, function and dysfunction of the ear, relatively high locus heterogeneity should also be expected.

\section{Acknowledgements}

We would like to express our gratitude to the members of all the families who participated in this study. We would like to thank KB Avraham for the use of primers of markers spanning known hearing impairment loci and Dr Glazer for performing the clinical evaluations of the BT 132A family members. We also thank Asher Berry for critical review of this manuscript. This work was supported in part by research grants from the Israel Science Foundation 1140041(BBT), the M inistry of Health 1140091(BBT), the Applebaum Foundation 1140111(BBT). This work was done as part of AA's PhD project.

\section{References}

1 Gorlin RJ, Toriello HV, Cohen M M: Hereditary Hearing Loss and its Syndromes. Oxford University Press: Oxford, 1995.

2 Vasiliki K, Petit C: The fundamental and medical impacts of recent progress in research on hereditary hearing loss. Hum $\mathrm{Mol}$ Genet 1998; 7: 1589-1597.

3 Keats $\mathrm{BJ}$, Berlin $\mathrm{Cl}$ : Genomics and hearing impairment. Genome Res 1999; 9: 7-16.

4 Hereditary Hearing Loss home page (Van Camp G, Smith RJH) http://dnalab-www.uia.ac.be/dnalab/hhh.

5 Baldwin CT, Weiss S, Farrer LA et al: Linkage of congenital, recessive deafness (DFNB4) to chromosome 7q31 and evidence for genetic heterogeneity in the Middle Eastern Druze population. Hum Mol Genet 1995; 4: 1637-1642.

6 Sambrook J, Fritsch EF, Maniatis T: M olecular Cloning: A Laboratory Manual, 2nd edn, Cold Spring Harbor Press: Cold Spring Harbor, NY, 1989.

7 Kelsell DP, Dunlop J, Stevens HP et al: Connexin 26 mutations in hereditary non-syndromic sensorineural deafness. Nature 1997; 387: 80-83.

8 Everett LA, Glaser B, Beck JC et al: Pendred syndrome is caused by mutations in a putative sulphate transporter gene (PDS). Nat Genet 1997; 17: 411-422.

9 Yasunaga S, Grati M, Cohen-Salmon M et al: A mutation in OTOF, encoding otoferlin, a FER-1-like protein, causes DFNB9, a nonsyndromic form of deafness. Nat Genet 1999; 21: 363-369.

10 Storm K, Wilcox S, Flothmann K, Van Camp G: Determination of the carrier frequency of the common connexin-26 30delG mutation in the Belgian population using easy and reliable screening method. Hum Mut 1999; 14(3): 263-266.

11 Sheffield VC, Beck JS, Kwitek AE, Sandstrom DW, Stone EM: The sensitivity of single-strand conformation polymorphism analysis for the detection of single base substitutions. Genomics 1993; 16: 325-332.

12 Krawczak M, Reiss J, Cooper DN: The mutational spectrum of single base-pair substitutions in mRNA splice junctions of human genes: causes and consequences. Hum Genet 1992; 90: 41-54.

13 Human Gene Mutation Database (Cooper DN, Ball EV, Stenson PD, Krawczak M, with the assistance of Fenton I, Abeysinghe S) http://www.uwcm.ac.uk/uwcm/mg/ search/5584511.html.

14 Li XC, Everett LA, Lalwani AK et al: A mutation in PDScauses nonsyndromic recessive deafness. Nat Genet 1998; 18: 215-217.

15 Usami S, Abe S, Weston MD, Shinkawa H, Van Camp G, Kimberling WJ: Non-syndromic hearing loss associated with enlarged vestibular aqueduct is caused by PDS mu. Hum Genet 1999; 104: 188-192.

16 Denoyelle F, Lina-Granade G, Plauchu $\mathrm{H}$ et al: Connexin 26 gene linked to a dominant deafness. Nature 1998; 393: 319-320.

17 Maestrini E, Korge BP, Ocana-SierraJ et al: A missense mutation in connexin 26, D66H, causes mutilating keratoderma with sensorineural deafness (Vohwinkel's syndrome) in three unrelated families. Hum Mol Genet 1999; 8: 1237-1243.

18 Heathcote K, Syrris P, Carter ND, Patton MA: A connexin 26 mutation causes a syndrome of sensorineural hearing loss and palmoplantar hyperkeratosis. J Med Genet 2000; 37: 50-51. 
19 The connexin 26 (GJB2)-deafness homepage (R (Kelly) Rabionet and the Deafness Research Group Estivill X, Gasparini P and Lench N) http://www.iro.es/cx26deaf.html.

20 Denoyelle F, Weil D, Maw MA et al: Prelingual deafness: high prevalence of a 30delG mutation in the connexin 26 gene. Hum Mol Genet 1997; 6: 2173-2177.

21 Zelante L, Gasparini P, Estivill $X$ et al: Connexin 26 mutations associated with the most common form of non-syndromic neurosensory autosomal recessive deafness (DFNB1) in Mediterraneans. Hum M ol Genet 1999; 6: 1605-1609.

22 Denoyelle F, Marlin S, Weil D et al: Clinical features of the prevalent form of childhood deafness, DFNB1, due to a connexin26 gene defect: implications for genetic counselling. Lancet 1999; 353: 1298-303.

23 Cohn ES, Kelley PM, Fowler TW et al: Clinical studies of families with hearing loss attributable to mutations in the connexin 26 gene (GJB2/DFNB1). Pediatrics 1999; 103: 546-550.

24 Estivill X, Fortina $P$, Surrey $S$ et al: Connexin-26 mutations in sporadic and inherited sensorineural deafness. Lancet 1998; 351: 394-398.

25 Kelley PM, Harris DJ, Comer BC et al: Novel mutations in the connexin 26 gene (GJB2) that cause autosomal recessive (DFNB1) hearing loss. Am J Hum Genet 1998; 62: 792-799.
26 Green GE, Scott DA, MCDonald JM, Woodworth GG, Sheffield VC, Smith RJ: Carrier rates in the midwestern United States for GJB2 mutations causing inherited deafness. J Am Med Assoc 1999; 281(23): 2211-2216.

27 Sobe T, Erlich P, Berry A et al: High frequency of the deafnessassociated 167delT mutation in the connexin 26 (GJB2) gene in Israeli Ashkenazim. Am J Med Genet 1999; 86: 499-500.

28 Bach G, Moskowitz SM, Tieu PT, Matynia A, Neufeld EF: Molecular analysis of Hurler syndrome in Druze and Muslim Arab patients in Israel: multiple allelic mutations of the IDUA gene in a small geographic area. Am J Hum Genet 1993; 53: 330-338.

29 Heinisch U, Zlotogora J, Kafert $\mathrm{S}$ et al: Multiple mutations are responsible for the high frequency of metachromatic leukodystrophy in a small geographic area. Am J Hum Genet 1995; 56: 51-57.

30 Carrasquillo MM, Zlotogora J, Barges S, Chakravarti A: Two different connexin 26 mutations in an inbred kindred segregating non-syndromic recessive deafness: implications for genetic studies in isolated populations. Hum Mol Genet 1997; 6: 2163-2172. 